308 Filllung des Silbers mit essigsaurem Eisenoxydul.

\begin{tabular}{|c|c|c|c|}
\hline $\begin{array}{l}\text { Feste Bestandtheile } \\
\text { in } 18 \text { Pfund }\end{array}$ & $\begin{array}{c}\text { Vor dem Düngen } \\
15,20 \mathrm{Gr} \text {. }\end{array}$ & $\begin{array}{c}\text { Nach dem } \\
27,500\end{array}$ & $\begin{array}{l}\text { Düngen } \\
\text { Gr. }\end{array}$ \\
\hline Organische Materien & $3,40 \mathrm{Gr}$. & 7,800 & Gr. \\
\hline Kieselsäure........ & $0,90 \quad "$ & 0,700 & $"$ \\
\hline Kieselsaure Thonerde. & $0,40 " \prime$ & 0,200 & $"$ \\
\hline Eisenoxyd $\ldots \ldots \ldots$ & $2,10 " \prime$ & 2,250 & $" \prime$ \\
\hline Chlormagnesium. & 1,12 & - & $"$ \\
\hline Magnesia? & - & 1,690 & $"$ \\
\hline Chlornatrium . . & 1,80 & 2,615 & " \\
\hline Chlorcalcium. & 3,00 & 2,107 & $"$ \\
\hline Kohlensaurer Kalk & . - & 2,700 & $"$ \\
\hline Schwefelsanre Thonerde. & . $0,85 "$ & - & " \\
\hline Phosphorsaurer Kalk. . & $0,30 \quad n$ & 3,100 & $"$ \\
\hline Phosphorsaure 'Thonerde & - & 0,450 & $"$ \\
\hline Phosphorsaure Magnesia. & $\ldots-$ & 1,800 & $"$ \\
\hline
\end{tabular}

Der Verfasser schliesst daraus, dass durch die Auflösung cines nicht unbeträchtlichen Theils der Dingerbestandtheile durch das Wasser der Nutzen des Diingers sehr vermindert wiirde und glaubt, dass es vorziiglicher sei, häufig aber mit geringern Mengen zu diingen. als nach der gewöhnlichen Methode. (Phil. Journ. and Transact.3. Ser. 30. p. 30. - Pharm. Centrbl. 1847. Nr. 25.) li.

\title{
Fällung des Silbers mit essigsaurem Eisenoxydul.
}

Man löst nach Kessler die Kupfer oder Blei enthaltenden Silberlegirungen in so wenig als möglich Salpctersäure auf, verdïnnt dic Lösung mit der 10- oder 20 fachen Menge Wasser und setzt dann so lange essigsaures Eisenoxydul hinzu, als cin Niederschlag entsteht. Dor Niederschlag wird zuerst mit Wasser, dem man etwas Essigsiure zugeselzt hat, und nachher mit durch Schwefelsäure schwach angesäuertem Wasser so lange ausgewaschen, bis in dem Aussiisswasser durch Blutlaugensalz kein Niederschlag mehr entsteht. Oekonomischer kann man noch verfahren, wenn man das salpetersaure Silberoxyd mit $60 \mathrm{mal}$ so viel, als es Silber enthält, Wasser verdünnt, und dann 4 mal so viel, als der Silbergehalt beträgt, krystallisirten Eisenvitriol, den man zuvor in Wasser zu ciner klaren Flüssigkeit gelost hat, und zuletzt noch einige Tropfen von einer essigsauren Eisenoxydullösung hinzuselzt.

Ausserdem eignet sich das essigsaure Eisenoxydul noch vorzüglich zur Ausfällung des Platins aus seinen Lösungen, welche bei gelinder Erwärmung derselben leicht und vollständig erfolgt. (Le Technol.1847. - Polyt. Centrbl. 1847. Lief. 11.) 